\title{
Enhancing Hydropower Modeling in Variable Generation Integration Studies
}

\author{
Eduardo Ibanez $^{\mathrm{a},+}$, Timothy Magee ${ }^{\mathrm{b}}$, Mitch Clement ${ }^{\mathrm{b}}$, \\ Gregory Brinkman ${ }^{a}$, Michael Milligan ${ }^{a}$, and Edith Zagona ${ }^{b}$ \\ ${ }^{a}$ National Renewable Energy Laboratory \\ 16253 Denver West Pkwy., Golden, CO 80401 USA \\ Email: eduardo.ibanez@nrel.gov, gregory.brinkman@nrel.gov, michael.milligan@nrel.gov \\ ${ }^{\mathrm{b}}$ Center for Advanced Decision Support for Water and Environmental Systems, University of Colorado \\ 421 UCB, Boulder, CO 80309, USA \\ Email: magee@colorado.edu, mitch.clement@colorado.edu, zagona@colorado.edu \\ ${ }^{+}$Corresponding author: Eduardo Ibanez \\ 16253 Denver West Pkwy., Golden, CO 80401 USA \\ Phone: +1-303-384-6926, Email: eduardo.ibanez@nrel.gov
}

\begin{abstract}
${ }^{1}$
The integration of large amounts of variable renewable generation can increase the demand on flexible resources in the power system. Conventional hydropower can be an important asset for managing variability and uncertainty in the power system, but multipurpose reservoirs are often limited by nonpower constraints. Previous large-scale variable generation integration studies have simulated the operation of the electric system under different penetration levels but often with simplified representations of hydropower to avoid complex nonpower constraints. This paper illustrates the value of bridging the gap between power system models and detailed hydropower models with a demonstration case. The United States Western Interconnection is modeled with PLEXOS, and ten large reservoirs on the Columbia River are modeled with RiverWare. The results show the effect of detailed hydropower modeling on the power system and its benefits to the power system, such as the decrease in overall production cost and the reduction of variable generation curtailment.
\end{abstract}

\section{Keywords}

Hydroelectric power generation, optimization, power system modeling, renewable energy sources, reservoirs.

\begin{tabular}{cl}
\hline${ }^{1}$ Abbreviations & \\
\hline BAU & Business as usual \\
BPA & Bonneville Power Administration \\
CC & Combined cycle \\
CT & Combustion turbine \\
DR & Demand response \\
PNW & Pacific Northwest \\
PV & Photovoltaic \\
TDG & Total dissolved gas \\
TEPPC & Transmission Expansion Planning Policy Committee \\
WECC & Western Electricity Coordinating Council \\
VG & Variable generation \\
WWSIS-2 & Western Wind and Solar Integration Study, Phase 2
\end{tabular}

(C) 2014. This manuscript version is made available under the Elsevier user license http://www.elsevier.com/open-access/userlicense/1.0/ 


\section{Introduction}

Integrating large amounts of wind and solar energy into the electric system can increase the demand for flexible resources. Variable generation (VG), such as wind and photovoltaic (PV) solar power, is both variable and uncertain, that is, their output changes over time due to their dependency on weather phenomena and cannot be fully forecasted. As a result, the remainder of the electric generation mix needs to balance the more variable net load (load minus VG generation) [1-3].

Hydropower generation is already part of the generation mix and is particularly abundant in the western United States, the geographic focus of the example presented in this paper. However, electricity generation is commonly only one of many purposes of reservoirs, which include an ever-growing, complex mix of power and nonpower objectives and constraints, including the Endangered Species Act and additional environmental objectives, navigation, flood control, water supply, and recreation, among others. Generally, these nonpower objectives and constraints prevail over the generation of electricity and prevent utilization of the full physical flexibility that hydropower can provide.

Both the power system and hydropower basins are complex systems with competing objectives and numerous constraints. Capturing these complexities in one single model has not been achieved to date, especially on a larger scale. Thus, often a simplified version of the one model is included in the other. The purpose of this paper is to bridge the gap between two existing models with a systematic approach that takes full advantage of their strengths. The approach is applied to a large scale system with hydropower and VG and demonstrates that hydropower can play a significant role in the integration of VG when it is correctly modeled.

Previous studies have developed methods aimed at improving the coordination of hydro operations with VG, particularly wind. One set of these methods optimizes bids into electricity markets from combined wind-hydro systems with stochastic wind inputs. The algorithms presented in [4] and [5] use hydro to meet the imbalance from wind forecast error and thus reduce imbalance penalties when such operations would improve the economic outcome of the combined system. In [6] and [7] transmission congestion is considered. The hydro producer can adjust its bid to relieve congestion and reduce wind curtailment in exchange for a payment from the wind producer. In [8] the optimization problem includes a constraint on the acceptable risk of not meeting a target payoff when scheduling combined wind and hydro.

Another set of methods coordinates hydro, wind and thermal resources to meet a specified power demand (load). The methodology in [9] commits available hydropower units if wind output is below a threshold and uses additional hydropower units for peaking when necessary in order to improve system reliability. A particle swarm optimization presented in [10] minimizes the cost of operating thermal units when meeting a load by coordinating wind, thermal and hydropower resources. The model is decomposed into two sub-problems with objectives of minimizing variation of thermal generation and maximizing the use of water available for hydro generation.

The aforementioned studies are designed to improve coordinated scheduling and operations of wind, hydropower and the thermal fleet in an operational context. As measured by their stated objectives all demonstrate 
improvements in the coordinated wind and hydropower systems, but do not provide an assessment of the performance of the wider electric system in the context of increased VG. These studies have not considered the effects of VG integration on an extensive grid scale, nor employed a representation of the complete power system including a full representation of other generating units, ancillary services and dynamic transmission constraints.

A significant number of large-scale studies have simulated the operation of the electric system under different levels of VG penetration. In the United States, these include the Western Wind and Solar Integration Study [11],[12], Eastern Wind Integration and Transmission Study [13], New England Wind Integration Study [14], and California's Integration of Renewable Resources [15]. All of these studies found that the integration of renewables is facilitated with a more flexible fleet of conventional generators. Yet, due to the complex mix of nonpower constraints, hydropower representation in these electric sector models is typically simplified, leading to under- or over-constrained estimates of the flexibility available in reservoirs. In both cases, the results of the studies are influenced by these assumptions.

Results from the International Energy Agency Task 24 Integration of Wind and Hydropower Systems Final Technical Report are summarized in [16]. Case studies from seven countries show that hydropower systems can provide much of the flexibility required for integrating large amounts of wind generation. The report acknowledges, however, the need for improvement in the modeling the physical characteristics and operating constraints of hydro systems in wind integration studies.

The methodologies presented in [4-10] include basic constraints on the hydropower system, such as water balances, minimum and maximum storage volumes and minimum and maximum discharge rates. Limits on storages and discharges are included as constant values and typically represent the physical limitations of the system. Exceptions include [4] and [5] in which time-varying constraints on discharge represent non-power policy constraints. Also, a constraint on total discharge volume for the simulation period is included in [10] to represent limits due to non-power water uses. In all cases, these are hard constraints. However, the actual operating policies for most hydro systems include competing water management objectives at varying levels of priority. Modeling these objectives of the hydro system as hard constraints cannot capture the realistic complexity of these policies and the operations that they implement.

Modeling of hydro operations is a well-established field but has not been incorporated widely into the electric sector primarily because both electrical system models and hydropower models are complex and are used for different purposes. RiverWare [17], in particular, is a river and reservoir modeling tool developed by the Center for Advanced Decision Support for Water and Environmental Systems authors of this paper, sponsored by the Tennessee Valley Authority, Bureau of Reclamation, and the U.S. Army Corps of Engineers, and used by these agencies and many others [18],[19]. Several RiverWare models are used on an ongoing basis for planning or operations such as models of the Tennessee River, Colorado River, the Upper Rio Grande River, the Truckee-Carson Basin, and the Colorado River in Texas. The Tennessee Valley Authority has used RiverWare to optimize hydropower while preferentially satisfying the nonpower constraints of multi-purpose reservoirs [20]. Due to the complex nature of the electric system, proxies are often utilized with varying degrees of fidelity.

The work described in this paper is motivated by the desire to determine the extent to which a full-scale electricity production simulation is able to accurately capture the nuances of the hydro system's constraints and the potential for improvement of the electricity production modeling so that the impacts of VG can be more accurately captured. We present a novel approach that bridges the gap between the two worlds by combining the hydro modeling system RiverWare [17] with the power system production model PLEXOS [21]. The methodology herein presented can be extrapolated to any combination of hydro reservoir optimizer and power systems production 
cost model. The final objective is to optimize the participation of hydro power facilities in the electric sector while meeting the aforementioned nonpower constraints, thus yielding a more realistic representation of the contribution of hydropower to the system flexibility, maximizing revenues to hydro operators, and enabling the integration of large amounts of VG energy. This paper shows the effects on the electrical system resulting from using RiverWare scheduling instead of a simplified hydro model as used in previous studies.

The remainder of the paper is organized as follows: Section 2 describes the methodology and software simulation tools used, Section 3 presents the case study in this paper, Section 4 summarizes the results, and Section 5 presents the conclusions.

\section{Methodology}

This section summarizes the steps in our proposed approach to integrate two simulation models, one that models the power system and one that optimizes the operation of a series of hydro facilities. Even though two particular software implementations are used in this paper, the methodology can be generalized to any pair of model implementations.

\subsection{Production cost model of the power system in PLEXOS}

PLEXOS [21] is a commercial production cost model that models the unit commitment and dispatch of generators in the electric power system. It is developed and commercialized by Energy Exemplar and used by industry and academia throughout the world. The optimization algorithm in PLEXOS seeks to minimize the overall cost of operating the system. The model uses a deterministic mixed integer linear program to minimize the cost to produce energy and serve all of the demand and ancillary services in the electric power system. The main decision variables are generation by generator, status (on/off), transmission flows, procurement or reserves, charging/discharging of storage (e.g., pumped-hydro, batteries). The generators on the system are committed using both day-ahead (for coal and nuclear generators) and 4-hour-ahead (for gas combined cycle and steam units) forecasts for wind and solar generation. The model then dispatches the system using actual estimates for wind and solar generation.

The following is a list of the main generators inputs considered in a PLEXOS simulation and represent inputs to the model:

- Variable operation and maintenance costs

- Fuel costs

- Heat rate, which can be define as a curve that varies with the loading in the generator

- Start-up costs

- Capacity (maximum output)

- Minimum stable level (or minimum generation when the unit is on)

- Start-up, minimum up and minimum shutdown times

- Ramping limits

- Ability to provide spinning reserves

VG is limited by the available underlying resource and is provides as power time series. These generators have a zero marginal costs so they are typically dispatched first by the optimization. However, wind and solar generators are allowed to curtail their output if it is beneficial to the system. This usually happens in high-penetration instances in regions with transmission constraints. Under high presence of renewables, conventional generators could be backed down to their minimum stable level or recommitted. The optimization can analyze whether 
curtailing VG (which have zero marginal cost) is more beneficial to the system than shutting down and restarting generators a few hours later.

For this study, the PLEXOS model was optimized over the entire Western Interconnection, which includes the western portion of the United States and parts of Canada and Mexico. The model was developed for Phase 2 of the Western Wind and Solar Integration Study (WWSIS-2) by NREL [12]. The project methods and results were overseen by a Technical Review Committee comprised of more than 50 professionals from utilities, system operators, research institutions, universities and federal. In turn, this model is largely based upon Western Coordinating Council's (WECC's) Transmission Expansion Planning Policy Committee (TEPPC) 2020 model [22], which is developed directly with input from utilities, balancing authorities and system operators in the Western Interconnection and vetted through a public stakeholder process.

This full representation of the Western Interconnection allows the model to optimize imports and exports to the study region instead of having to simplify those. The DC transmission model contains 20 zones (Fig. 1) and roughly 2000 generators are modeled using typical security-constrained unit commitment constraints such as start-up times and costs, upward/downward ramp limits, and minimum generation levels.

In the absence of detailed data, hydropower modeling is simplified following practices from the WECC's TEPPC [22], which assumes that a significant portion of available hydro generators (representing $40 \%$ of the energy produced) have profiles fixed to historical operation and cannot be changed because of institutional, environmental, or other constraints. The WECC modeling dispatches the remaining hydro units using methods developed by the Hydro Modeling Task Force [23] that dispatch some of the hydro in response to price or based on statistical characterizations of dispatchability.

The typical hydro dispatch method used in PLEXOS optimizes the usage of hydro subject to monthly maximum and minimum power outputs as well as monthly energy limits for the dispatchable units. This study starts with the same assumptions and uses monthly hydro parameters based on the Energy Imbalance Market study [24] WWSIS2 [12]. Each month is optimized individually for 15 time slices that represent typical hours for the month. Daily hydro generation resulting from the monthly optimization is input into the day-ahead unit commitment, which optimizes over a 48-hour time horizon. Other input parameters are based on assumptions from WWSIS-2.

\subsection{Reschedule hydropower in RiverWare}

\subsubsection{Information sent from PLEXOS to RiverWare}

Once the PLEXOS simulation is complete, we proceed to communicate a number of parameters to RiverWare. We constrain RiverWare to have the same total weekly hydropower generation as the initial PLEXOS run, i.e., the total production from the cascading system remains the same, but individual reservoirs can vary the amount of energy produced. This allows a comparison based solely on temporal and spatial changes in hydro generation, but takes advantage of the more accurate representation of the more cascading system and eliminates the potential benefit of changing total hydropower generation.

RiverWare represents the value of hydro generation [25],[26] as the revenue resulting from the sale of power and tries to maximize this quantity as one of the objectives. Revenue is calculated as the product of generation and electricity price, i.e., the locational marginal price in a power systems simulation. Electricity prices are dependent on the generation stack and can be affected by the amount of hydropower being generated. To capture this behavior, RiverWare utilizes price-generation curves that can be different for each hour of the optimization. The idea behind these curves is that, because the marginal operation cost of hydro is very low, increasing its 
production at a point in time will depress prices and reducing the production will cause a more expensive unit to be utilized.

Simple price curves are derived based on PLEXOS results. We perform a regression analysis to find the correlation between prices and load levels. Price curves are developed for each hour following the steps shown in Fig. 2: (1) average price and generation level are determined for each hour; (2) depth is added linearly using the regression coefficient previously calculated; (3) prices are not allowed to be negative; and (4) prices are capped at the marginal cost of demand response $(\$ 195 / \mathrm{MWh})$, which is the most expensive resource.

\subsubsection{RiverWare Model}

RiverWare's [17] optimization component is designed to optimize the multiple goals associated with multi-purpose reservoirs in a way that is consistent with the policies of the organizations that manage reservoir systems. Typically, agencies and operators prioritize these policies to first satisfy nonpower constraints to the extent possible. Any remaining flexibility is used to maximize the economic value of the system, by maximizing the revenue from hydropower generation. Faithfully representing these policy priorities within a model is essential for creating a realistic model.

RiverWare meets this modeling need with Preemptive Linear Goal Programming, which solves a series of linear programs corresponding to different priority levels with separate objective functions [27]. An objective function can be an explicit maximization or minimization of a function. Alternatively, a set of soft constraints can be converted to an objective function that maximizes their degree of satisfaction.

For example, a minimum flow constraint is converted to an objective function for priority level pri by writing

$$
\begin{gathered}
\text { maximize Satisfaction }_{\text {pri }} \\
\text { Outflow }_{\text {reservoir }, t} \geq \text { minimum }_{\text {flow }} \text { reservoir }_{\text {Satisfaction }} \text { pri }_{\text {Breservoir }, t} \text { (r) } \\
0 \leq \text { Satisfaction }_{\text {pri }} \leq 1
\end{gathered}
$$

This maximin objective function, is maximized and then, the limiting, least satisfied constraint(s) are locked in place at their maximal satisfaction value by modifying the constraints. A new maximin objective is created for the remaining non-limiting constraints. This process is repeated until all constraints are locked in place or are fully satisfied. We term this complete procedure a "repeated maximin" objective [27].

Ideally, all of the soft constraints will be fully satisfied, but in the event that this is not possible, RiverWare will come as close as possible. Finally, higher priority objectives constrain the solutions available to lower priority objectives.

A contribution of this research is combining this detailed modeling of soft nonpower constraints and their priorities in the hydropower system with a model of the larger power system. Without this detail, power system models can only coarsely approximate the operations and the actual flexibility and limitations of a hydropower system.

When modeling a hydro system in the context of a power system that includes non-hydro power sources, the nonpower objectives of the hydro system have the highest priorities and the hydropower objective becomes the value of hydropower to the entire power system. At optimality, the marginal cost of additional generation at each time period within the rest of the power system will equal the marginal value of additional hydropower generation. Similarly, the marginal cost of each additional ancillary service within the rest of the power system will equal the marginal value of providing that service with hydropower. 
For this research, we simplify the modeling in two ways. First, because the value of ancillary services produced by PLEXOS is very small, it is not modeled in RiverWare. Second, the maximization of hydro revenues in RiverWare is based on the marginal prices of system generation in the initial PLEXOS run with decreases in the value as hydropower generation increases, as described in the previous section. Thus, these prices are only an approximation of the optimal marginal prices that one could determine using repeated iterations between RiverWare and PLEXOS to converge on a solution.

The final step in RiverWare is a post-optimization simulation. This simulation removes minor approximation errors and makes related adjustments to the solution.

\subsubsection{Limit ramping}

Frequently, hydropower operators limit hourly ramping of turbine release and/or spill. In a discrete time step model, ramping is the absolute value of the first differential of flow. Initial results show that the highly variable nature of the electric system can produce hydro generation profiles with levels of ramping higher than historically observed. Thus, we have included hourly limits on ramping in all of the RiverWare runs.

In addition, operators often also limit arbitrary ramping up and down in adjacent time steps. Plant level ramping constraints indirectly reduce the number of starts and stops at a unit level. Starts and stops are known to increase the need for more frequent unit maintenance and associated costs, but the exact relationship is difficult to quantify.

In a discrete time step model, these ramping limits translate to constraints on the absolute value of the second differential of flow. The historical operation of the reservoirs described in the next section indicates that the average absolute value of the second differential is usually less than $2 \%$ of the maximum hourly ramp rate for each reservoir in our case study based on observed historical operations. This value allows normal peaking in response to prices, but significantly reduces arbitrary ramping up and down. We add these second differential constraints to the RiverWare model for our base runs (also referred to as "limited ramping" runs), but do not add them in our "unlimited ramping" runs. We will discuss the effect of these constraints in the results.

\subsection{Iterative process}

The two models can be iteratively run to improve the current solution. Once the hydro operation has been optimized in RiverWare, the resulting generation profiles meet all the required constraints and objectives and maximize the potential revenue from electricity production, given the price curves derived from PLEXOS. Those profiles are used as an input parameter to PLEXOS and the rest of the electric system operation is reoptimized, resulting in new commitment and dispatch patterns, along with new electricity price time series. The offer curves that are used as an input to RiverWare can then be updated and the process repeated following the diagram in Fig. 3.

With each iteration more information of the relationship between hydro generation and electricity prices is available to create the price curves that feed into RiverWare (Fig. 2). The iterative process can be said to have converged when the total production cost of two consecutive PLEXOS simulations is below the MIP gap set for the solver. At this point, the hydro profiles in the production cost simulation meet all the nonpower constraints included in RiverWare and the additional flexibility is utilized to increase the energy revenue for hydro generators. Even though the global optimality is not guaranteed by the process, the solution in each model will meet the nuances and set of constraints formulated in the other model without having to include them explicitly. Because of funds limitations, we ran RiverWare only once. 


\subsection{Validity tests}

This paper focuses on the development between a power systems and a hydrological model. PLEXOS and RiverWare were selected because they are two well-established models in their respective fields and the authors had done extensive work in the geographical area represented. A more extensive description of the individual models and the underlying data is contained in the following sections. A full validation of these models is beyond the scope of this paper.

However, some validity tests [28]-[30] can be applied based on the knowledge from the previous efforts that built these models:

- Structure verification: The models implement the physical representation of power and hydro systems, both of which have been extensively described in the literature, e.g., in [31],[32].

- Boundary verification: The hydrological model represents an entire river system, which is a closed system. The power systems model represents the entire Western Interconnection, precisely to avoid problems that could arise from representing the Northwest region in isolation. Furthermore, the paper studies how to better represent the nexus between the two models.

- Dimensional verification: As described earlier in the section, the number of equations in the models depends on the elements represented: number of generators, transmission, areas, reservoirs, etc.

- Parameter verification: Previous studies [12],[22], and the University of Colorado along with the Bonneville Power Administration (BPA) developed the models from the ground up. The data for different components in the power system were provided by their respective utilities and assembled by TEPPC, while BPA provided the parameters for the characterization of their reservoirs. The detailed data sources are listed in the next section.

- $\quad$ Extreme conditions: The power system representation was tested for all seasonal conditions, along with very high penetrations of VG. Similarly, the hydropower model was tested against multiple years of data, with different levels of water available.

- Behavioral validity: [12], [22] and the work with BPA compared the results from the simulations against past observed behavior and used the expertise of their reviewers from industry and academia to validate future conditions.

\section{Demonstration Case Description}

To demonstrate the value of enhanced hydropower modeling in VG integration, we select the Western Interconnection as the power system to model in PLEXOS, a region used in previous VG integration studies.

We select only part of the hydropower generation in the Western Interconnection for modeling within RiverWare. We limit our detailed hydropower modeling to a portion of the Pacific Northwest region (PNW), the BPA's marketing area, which "includes Oregon, Washington, Idaho, Montana west of the Continental Divide, and portions of Nevada, Utah, and Wyoming that lie within the U.S. Columbia River drainage basin" [33]. This region was selected in part because it relies heavily on both hydropower generation (44\%) and renewables (7\%), primarily wind, for firm energy [34]. We further limit our hydropower modeling to the ten largest federally owned reservoirs, the so called "Big Ten" reservoirs, managed by the BPA in coordination with the Bureau of Reclamation and the U.S. Army Corps of Engineers.

Fig. 4 shows the Big Ten, and the inset shows the PNW region. The reservoirs, shown in RiverWare in Fig. 4, are Lower Granite, Little Goose, Lower Monumental, and Ice Harbor on the Snake River and Grand Coulee, Chief 
Joseph, McNary, The Dalles, John Day, and Bonneville on the Columbia River. The operation and planning of these reservoirs are interconnected because the flows are relatively large compared to the storage capacity. Together, these reservoirs represent $85 \%$ of the hydropower in the Western Interconnection.

A high level view of the policies and their priorities in the RiverWare model are shown in Fig. 6 . The constraints include elevation minimum and maximum values; minimum outflows; allowable hourly and daily changes in outflows, elevations, and tailwater; guide curves; required spill for fish; limited spill for fish due to Total Dissolved Gas (TDG); and weekly flow targets.

The modeled physical characteristics of the hydro system are based on data obtained from BPA. These include elevation to storage content relationships, power characteristics and tailwater elevation curves and hydraulic routing lag times between reservoirs. The data is represented in discrete tabular format as in Table 1.

Similar discrete tables exist for tailwater elevation as a function of outflow and power as a function of gross operating head and turbine release. Linear interpolation is used for values between the table values. For this study, routing was modeled as a constant lag time, such as 1.50 hours, but more complex methods are available in RiverWare.

Nonpower constraints are based on Columbia Basin policies described in publicly available sources [35],[36]. The RiverWare optimization model of the Big Ten reservoirs was previously validated by BPA. The operators examined the RiverWare constraint, objectives, priorities, and data; designed specific test scenarios; and confirmed that RiverWare correctly modeled the system for those scenarios. However, BPA did not participate in this research nor the scenarios used. Consequently, the model roughly approximates the physical characteristics of the reservoirs and follows the general spirit of BPA's policies, but may diverge in significant ways. We consider the model to be accurate enough to study the effects on the grid and renewables of including more realistic constraints on hydropower generation. However, it would be a misuse of our results and an error-prone exercise to draw any conclusions about the BPA system or its operation.

We use two scenarios from WWSIS-2 in PLEXOS to represent two very different possible future operations: a business-as-usual (BAU) case that contains 13\% of VG wind and solar (based on the TEPPC scenario in WWSIS-2), and a high-wind scenario (based on WWSIS-2's HiWind). The main difference between the BAU and the HiWind scenarios is that the latter presents significant additional VG installed in the system, especially wind. For the remainder of this paper, the scenarios will be referred to as BAU and HiWind, respectively. Table 2 summarizes the VG penetration existing in both scenarios.

Load, wind, solar, and hydro profiles are based on the meteorology of the year 2006, although load levels were increased to match 2020 forecasts. Wind profiles were synthesized using a numerical weather prediction model [37], while solar data was produced by the National Renewable Energy Laboratory [38] based on the satellitederived irradiance generated by the State University of New York/Clean Power Research [39], which is available on a $10-\mathrm{km}$ grid at an hourly resolution. The study focuses on the week of April 20-27. Thus, the actual starting reservoir elevations and the hydrologic inflow from this period [40] are used in the RiverWare model. This is a period with significant inflow, but normal for April. Thus, one would expect the nonpower constraints to influence the solution without dominating it during this time period. In the power systems, spring season presents low loads and high VG potential, which can lead to challenging operations with high penetrations of VG.

The RiverWare model uses an hourly time step while PLEXOS uses several time steps ranging from monthly down to 5-minute intervals. 


\section{Results and Discussion}

This section presents the results of this study and their analysis. First, we summarize the original 5-minute PLEXOS dispatch; then we study the RiverWare results; finally, we analyze the effect of incorporating the hydro profiles optimized by RiverWare into PLEXOS. We find that production costs decrease with the RiverWare hydro profiles and VG curtailment decreases for the HiWind scenario.

\subsection{First PLEXOS simulation}

The first optimizations of the electric system (with default hydro assumptions) show how different the operation is in the two scenarios. Fig. 7 shows the BAU scenario, which, in spite of the significant amount of renewables present, closely resembles current operations: nuclear and coal units are base-loaded (and a number of them go in and out of maintenance), hydro follows the daily load patterns, and natural gas combined cycle (CCs) and combustion turbines (CTs) are used to balance the rest of the load. No major curtailment events are expected.

In contrast, the HiWind scenario (Fig. 8) shows a much more important penetration of VG during this week. Nuclear is still base-loaded, but coal generation levels vary greatly to accommodate the low-cost renewables. CC output is reduced dramatically, and we see instances of wind and solar power curtailment during the middle of the day (when both wind and solar are present) and at night (when the load is small). These curtailment events are driven both by minimum-generation episodes when conventional units back down to their minimum stable level and there are transmission constraints that do not allow excess generation to be exported to neighboring areas. The unit commitment and dispatch optimization finds more economical to temporarily curtail VG rather than decommitting a unit and start-up a new one a few hours later.

Table 3 summarizes the regression coefficients of the price-generation curves. These curves become an input to RiverWare and approximately determine how electricity LMPs decrease (increase) as hydro power generation increases (decreases), as explained in section 2.2.1. After careful examination of the production cost simulation results, it was determined that a simple regression of price versus generation could be achieved by separating times when demand response (DR) was called upon. The table shows that prices can be reduced further when DR is present, which is understandable given the high cost of DR. Without DR, price is less sensitive in the HiWind case because of the additional zero-cost wind available in the system.

\subsection{RiverWare simulation}

The total hydropower generation in RiverWare shows considerably more variation than the hydropower generation in the initial PLEXOS run. Without RiverWare, PLEXOS is forced to over constrain the hydro plants to prevent violation of non-power constraints. In contrast, RiverWare shows the generation can be more flexible while still satisfying the non-power constraints to the extent that hydrologic conditions permit. Fig. 9 illustrates the difference between the PLEXOS and RiverWare solutions for both scenarios. We observe changes in generation within the same days, but also from one day to another, driven primarily by the system value of hydropower.

The most influential non-power constraints in RiverWare were the TDG constraints required to reduce fish mortality. TDGs increase with increased spill, and RiverWare included both instantaneous and 12 hour rolling average spill constraints as a way to enforce he TDG constraints. The rolling average spill constraints at Little Goose and The Dalles could only be partially satisfied because of the hydrologic conditions. Even though the constraints were fully satisfied at the other reservoirs, the TDG constraints affected the generations at those reservoirs.

While Fig. 9 demonstrates the temporal differences in generation between PLEXOS and RiverWare, Fig. 10 illustrates the spatial shift in generation from some reservoirs to others in part caused by the TDG constraints. With a change in hydrologic conditions other policies in RiverWare could lead to similar spatial shifts in generation. 
An example of the spatial differences in generation caused by TDG constraints is that the TDG constraints are more restrictive at Grand Coulee than at Chief Joseph. Thus, the constraints tend to decrease spill at Grand Coulee while increasing generation with the opposite effects at Chief Joseph. Combined with the constraint that total RiverWare generation equal total PLEXOS generation, the TDG constraints lead to spilling approximately half of the outflow at Chief Joseph. Most of the other spatial shifts in this particular run are due to TDGs. This result is consistent with previous instances of generation being forced by TDG constraints, sometimes to the point of forcing curtailment of VG [41].

The spatial and temporal shifts in generation for the Columbia River reservoirs are shown in Fig. 11. For some reservoirs, the constraints in PLEXOS have very similar behavior to the RiverWare model. In others, there are very large differences.

\subsection{Effect of Limited Ramping}

In order to measure the effect of the constraints that prevent excessive ramping in the operation of hydro, RiverWare was run both with and without the ramping constraints described in Section 2.2.3. Fig. 12 shows the effect of the constraints on total hydropower generation for both the BAU and HiWind scenarios. The constraints result in noticeably smoother total hydropower generation that resembles historical operation of the reservoirs.

The effects of ramping constraints are even more dramatic for individual reservoirs. For example, the smoothing at Chief Joseph (Fig. 13) is far greater than the smoothing of the whole hydro system.

If we look at the hydro system in isolation from the rest of the power system, we can compare the RiverWare revenue from power production for the initial PLEXOS solution to the RiverWare solutions with and without ramping constraints. Table 4 shows the differences in RiverWare hydro revenues. In both scenarios, the assumptions that went into the PLEXOS model create a solution that was overconstrained in comparison with the more detailed modeling in RiverWare runs and thus the hydro revenue was lower than either RiverWare run. The hydro revenue in the RiverWare run with unlimited ramping was slightly higher than in the run constrained by limited ramping.

\subsection{RiverWare hydro profiles in PLEXOS}

In this last step, the PLEXOS simulation is rerun with the hydro profiles from RiverWare with and without limited ramping. Given that the results of the two cases are similar, only the limited ramping results (the more conservative, and arguably more realistic, of the two) are shown here.

For the remainder of this section, we will refer to the results from the first PLEXOS optimization (described in Section 4.1) as "PLEXOS" and we will use "RiverWare" for the PLEXOS reoptimization that utilizes the RiverWare hydro profiles (described in Section 4.2).

\subsubsection{Generation}

Table 5 summarizes the amount of energy produced by generator type. For the BAU scenario, we observe an increase in coal generation and a decrease in natural gas CC. In the HiWind scenario, there is a slight increase in net generation by renewables (especially wind and, to a lesser degree, PV) as well as gas CC and CT generators. There is a noticeable decrease in generation from coal units under this scenario.

The increase in VG net generation in the HiWind scenario is due to a decrease in curtailment for the HiWind scenarios (Fig. 14), from $4.3 \%$ to $3.6 \%$, a $16 \%$ reduction. For the BAU scenarios, curtailment remains stable at the $0.2 \%$ level. 
Fig. 15 shows how the reduction in curtailment in the HiWind scenario is achieved by the hydro redispatch. A reduction in generation during the night and midday hours helps to avoid hours with low load and high solar output, respectively, while an increase in the evening hours helps to capitalize on the higher electricity prices.

\subsubsection{Electricity prices}

Table 6 summarizes average marginal prices (weighted by load) for the Western Interconnection. In both the BAU and HiWind scenarios, we see a decrease of $\$ 2-3 / \mathrm{MWh}$. This is due mainly to a reduction in the number of hours with extreme high prices and a marginal increase in off-peak prices, as shown in the price duration curves (Fig. 16). This is achieved through the reshaped hydropower observed in Fig. 15.

Fig. 17 shows how some of the spikes in extremely high prices in the HiWind scenario are dampened when using the RiverWare hydro profiles. These spikes are primarily due to shortages in energy or reserve requirements that lead to activation of more expensive resources, such as DR, which is priced at $\$ 195 / \mathrm{MWh}$, and are caused by a combination of transmission constraints, forecast errors and, at times, because it is more economical to dispatch demand response for short amounts of time instead of starting a unit. The RiverWare solution reduced the need for the relatively expensive resources -such as demand response- by redispatching the hydro energy available, which was not possible in the PLEXOS case.

\subsubsection{Cost and emissions}

Table 7 summarizes the total production cost in the Western Interconnection for the study week. Cost includes terms for fuel costs, variable operation and maintenance costs, and cycling of thermal units (i.e., startup costs, startup fuel and ramping costs) [12],[42]. Total cost is reduced in both the scenarios. The savings are greater in the BAU scenario because of the significant switch from gas $\mathrm{CC}$ to coal units. In the HiWind scenario, gas $\mathrm{CC}$ units are backed down to a minimum level so the main savings come from the decrease in spilled VG energy.

Emissions were calculated for $\mathrm{CO}_{2}, \mathrm{NO}_{x}$, and $\mathrm{SO}_{2}$ (Fig. 18) and took into account the effects of cycling [12]. Because this is a coal-dominated system (Table 4), all three pollutants follow the behavior of coal in all scenarios, that is, there is an increase in the BAU cases and a decrease for the HiWind ones.

\section{Conclusions and Future Work}

This paper explores the potential benefits of combining a production cost simulation to represent the operations of the electric system (such as PLEXOS) coupled with a modeling tool for hydropower operations (in this case, RiverWare). The methodology presented here allows for the combined optimization of both systems and the utilization of their full representation of this complex system, as opposed to simplifications.

Two very different scenarios for the U.S. Western Interconnection were explored, one with relatively low amount of renewables and one with $33 \%$ renewable energy penetration. A significant portion (85\%) of the hydro in the interconnection was modeled in RiverWare with realistic power and nonpower objectives. In both scenarios, there was a significant benefit to the electric system due to the increased flexibility found in hydro, more specifically:

- In the BAU scenario, total productions costs were reduced by $2 \%$.

- The HiWind scenario saw a reduction of $16 \%$ in the amount of VG curtailed and a $0.6 \%$ decrease in total production costs.

- In both cases, extreme marginal price spikes were reduced.

This simulation was performed for a single spring week and we expect more moderate benefits during the summer months (when load levels are higher, more conventional units are committed, and need for flexibility is reduced). 
Future work will explore the optimization of the system for longer time frames and extract key characteristics in the operation of hydropower that can enhance its representation in electric simulations tools.

\section{Acknowledgement}

The authors acknowledge the support of the Joint Institute for Strategic Energy Analysis, which is operated by the Alliance for Sustainable Energy, LLC, on behalf of the U.S. Department of Energy's National Renewable Energy Laboratory, University of Colorado-Boulder, Colorado School of Mines, Colorado State University, Massachusetts Institute of Technology, and Stanford University. The authors would like to thank the Bonneville Power Authority (BPA) for their data and permission to use it.

\section{References}

[1] L.G. Daoutis, E.N. Dialynas. Impact of hybrid wind and hydroelectric power generation on the operational performance of isolated power systems. Electric Power Systems Research, Vol 79, No 10, October 2009, pp 1360-1373.

[2] J. G. Slootweg, W. L. Kling. The impact of large scale wind power generation on power system oscillations. Electric Power Systems Research, Vol 67, No 1, October 2003, pp. 9-20.

[3] L.G. Daoutis, E.N. Dialynas. Impact of hybrid wind and hydroelectric power generation on the operational performance of isolated power systems. Electric Power Systems Research, Vol 79, No 10, October 2009, pp 1360-1373.

[4] Angarita, J.M, and J.G. Usaola, "Combining Hydro-Generation and Wind Energy Biddings and Operation on Electricity Spot Markets," Electric Power Systems Research, vol. 77, pp. 393-400, 2007, doi: 10.1016/j.epsr.2006.03.019.

[5] Angarita, J.L., J. Usaola and J. Martinez-Crespo, "Combined Hydro-Wind Generation Bids in a Pool-based Electricity Market," Electric Power Systems Research, vol. 79, pp. 1038-1046, 2009, doi:10.1016/j.epsr.2009.01.002.

[6] Matevosyan, J. and L. Soder, "Short-term Hydropower Planning Coordinated with Wind Power in Areas with Congestion Problems," Wind Energy, vol. 10, no. 3, pp. 195-208, 2007, doi:10.1002/we.

[7] Matevosyan, J., M. Olsson, and L. Soder, "Hydropower Planning Coordinated with Wind Power in Areas with Congestion Problems for Trading on the Spot and the Regulating Market," Electric Power Systems Research, vol. 79, no. 1, pp 39-48, 2009, doi:10.1016/j.epsr.2008.05.019.

[8] Abreu, L.V.L, M.E. Khodayar, M. Shahidehpour and L. Wu, "Risk-Constrained Coordination of Cascaded Hydro Units With Variable Wind Power Generation," IEEE Transactions on Sustainable Energy, vol. 3, no. 3, pp. 359-368, 2012.

[9] Karki, R., P. Hu, and R. Billinton, "Reliability Evaluation Considering Wind and Hydro Power Coordination," IEEE Transactions on Power Systems, vol. 25, no. 2, pp 685-693, 2010.

[10] Wang, K.Y., X.J. Luo, L. Wu and X.C. Liu, "Optimal Coordination of Wind-Hydro-Thermal Based on Water Complementing Wind," Renewable Energy, vol. 60, pp. 169-178, 2013.

[11] GE Energy, "Western Wind and Solar Integration Study," National Renewable Energy Laboratory, Tech. Rep. SR-550-47434, May 2010, [Online]. Available: http://www.nrel.gov/docs/fy10osti/47434.pdf

[12] Lew, D., Brinkman, G., Ibanez, E., Florita A., Heaney, M., Hodge, B. M., Hummon, M., Stark, G., King, J., Lefton, S.A., Kumar, N., Agan, D., Jordan, G., Venkataraman, S. "Western Wind and Solar Integration Study Phase 2." National Renewable Energy Laboratory, Tech. Rep. TP-5500-55588, 2013, [Online] Available: http://www.nrel.gov/docs/fy13osti/55588.pdf

[13] Enernex, "Eastern Wind Integration and Transmission Study," National Renewable Energy Laboratory, Tech. Rep. SR-5500-47078, 2011, [Online] Available: http://www.nrel.gov/docs/fy11osti/47078.pdf

[14] GE Energy, "New England Wind Integration Study," New England Independent System Operator, 2010 [Online] Available: http://www.isone.com/committees/comm wkgrps/prtcpnts comm/pac/reports/2010/newis report.pdf 
[15] California ISO, "Integration of Renewable Resources: Operational Requirements and Generation Fleet Capability at 20\% RPS" [Online] Available: http://www.caiso.com/2804/2804d036401fo.pdf

[16] Acker, T.L., Robitaille, A., Holttinen, H., Piekutowski, M. and Tande, J.O.G., "Integration of Wind and Hydropower Systems: Results of IEA Wind Task 24," Wind Engineering, vol. 36, no. 1, pp. 1-18, 2012.

[17] E. Zagona (2013) RiverWare, www.riverware.org

[18] E. Zagona, T. Magee, D. Frevert, T. Fulp, M. Goranflo and J. Cotter. "RiverWare," in Watershed Models, V. Singh \& D. Frevert Eds., Boca Raton, FL: Taylor \& Francis/CRC Press, 2005, pp. 527-548.

[19] E. Zagona, T. Fulp, R. Shane, T. Magee, and H. Goranflo, "RiverWare: A Generalized Tool for Complex Reservoir Systems Modeling," Journal of the American Water Resources Association, vol. 37, no. 4, pp. 913-929, 2001.

[20] T. Magee, S. Jacks, and E. Zagona, "Scheduling TVA's Reservoirs with RiverWare," in Proc. of the Fourth Federal Interagency Hydrologic Modeling Conference, Las Vegas, NV, Jun 27 - Jul 1, 2010.

[21] Energy Exemplar, PLEXOS, http://energyexemplar.com/software/

[22] Western Electricity Coordinating Council, Transmission Expansion Planning Policy Committee, http://www.wecc.biz/committees/BOD/TEPPC/default.aspx

[23] Western Electricity Coordinating Council, Transmission Expansion Planning Policy Committee, Hydro Modeling Task Force, http://www.wecc.biz/committees/BOD/TEPPC/Pages/HMTF.aspx

[24] Milligan, M.; Clark, K.; King, J.; Kirby, B.; Guo, T.; Liu, G. (2013). Examination of Potential Benefits of an Energy Imbalance Market in the Western Interconnection. 122 pp.; NREL Report No. TP-5500-57115.

[25] Wolfgang O, Haugstad A, Mo B, Gjelsvik A, Wangensteen I, Doorman G. Hydro Reservoir Handling in Norway Before and After Deregulation. Energy 2009, 34:1642-1651.

[26] Stefan Jaehnert, Ove Wolfgang, Hossein Farahmand, Steve Voller, Huertas-Hernando D. Transmission expansion planning in Northern Europe in 2030 - methodology and analyses. Energy Policy 2013, 61:125139.

[27] E. Eschenbach, T. Magee, E. Zagona, M. Goranflo, and R. Shane, "Goal Programming Decision Support System for Multiobjective Operation of Reservoir Systems," Journal of Water Resources Planning and Management, vol. 127, no. 2, pp. 108-120, 2001.

[28] G. B. Kleindorfer, L. O'Neill, and R. Ganeshan, "Validation in simulations: Various positions in the philosophy of science," Management Science, vol. 44, no. 8, pp. 1087-1099, 1998.

[29] M. Pidd, "Why modeling and model use matter," Journal of the Operational Research Society, vol. 1, pp. 14-24, 2010.

[30] H. Qudrat-Ullah, and S. BaekSeo, "How to do structural validity of a system dynamics type simulation model: The case of an energy policy model," Energy Policy, vol. 38, no. 5, pp. 2216-2224, 2010.

[31] A. R. Bergen, and V. Vittal, Power Systems Analysis, 2nd ed., Upper Saddle River, NJ: Prentice Hall, 1999.

[32] J. Zhen-Gang, Hydrodynamics and Water Quality: Modeling Rivers, Lakes, and Estuaries, New York, NY: Wiley, 2008.

[33] Bonneville Power Administration, "2012 Pacific Northwest Loads and Resources Study (2012 White Book)," Portland, OR, DOE/BP-4476, Oct. 2012, p.3.

[34] Ibid., p.68.

[35] Bonneville Power Administration; U.S. Bureau of Reclamation; U.S. Army Corps of Engineers. 2012 Water Management Plan, December 31, 2011, [Online] Available: http://www.nwdwc.usace.army.mil/tmt/documents/wmp/2012/

[36] U.S. Army Corps of Engineers, "Summary of Columbia River Flood Control Data." [Online] Available: http://www.nwd-wc.usace.army.mil/report/colsum/

[37] 3TIER, "Development of Regional Wind Resource and Wind Plant Output Datasets," National Renewable Energy Laboratory, Tech. Rep. SR-550-47676, 2010, [Online] Availble: www.nrel.gov/docs/fy10osti/47676.pdf

[38] K. Orwig, M. Hummon, B.-M. Hodge, and D. Lew, "Solar data inputs for integration and transmission planning studies," 1st Int. Workshop on Integration of Solar Power into Power Systems Proceedings, Aarhus, Denmark, Oct. 2011.

[39] S. Wilcox et al., "Completing Production of the Updated National Solar Radiation Database for the United States," Solar 2007 Conference Proceedings, Cleveland, OH, July 8-12, 2007. 
[40] University of Washington School of Aquatic and Fishery Sciences, "Columbia Basin Research DART (Data Access in Real Time)" [Online] Available: http://www.cbr.washington.edu/dart/inventory

[41] Bonneville Power Administration, "Seasonal Power Oversupply in 2012," Portland, OR, DOE/BP-4485, Feb 2013.

[42] Kumar, N.; Besuner, P.; Lefton, S.; Agan, D.; Hilleman, D. "Power Plant Cycling Costs," National Renewable Energy Laboratory, Tech. Rpo. SR-5500-55433, 2012, 83 pp, [Online]. Available: http://www.nrel.gov/docs/fy12osti/55433.pdf 


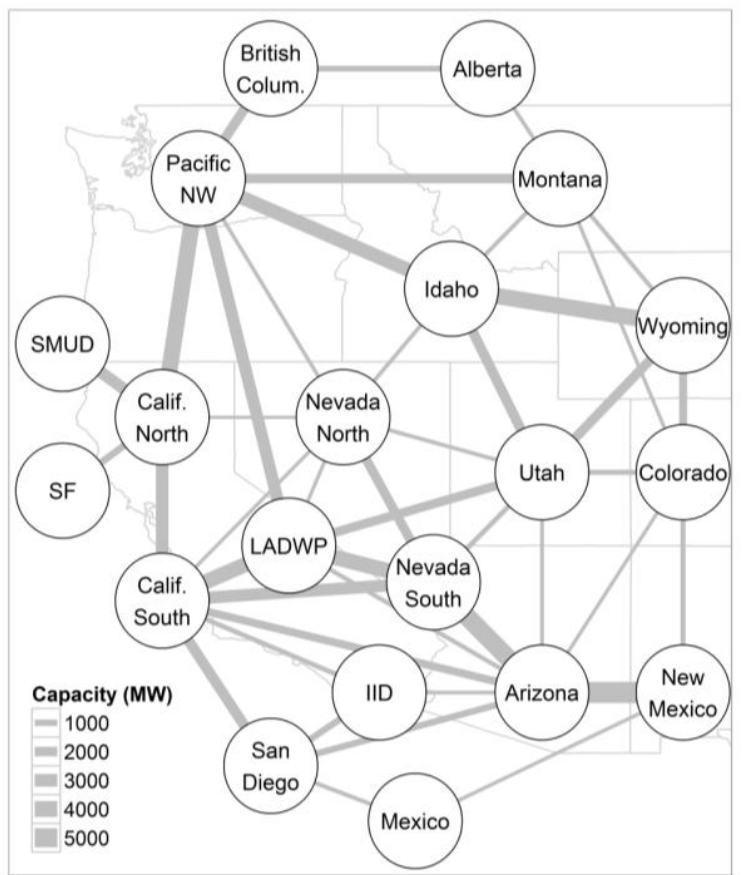

Figure 1. Zonal configuration of the Western Interconnection with available transfer capabilities

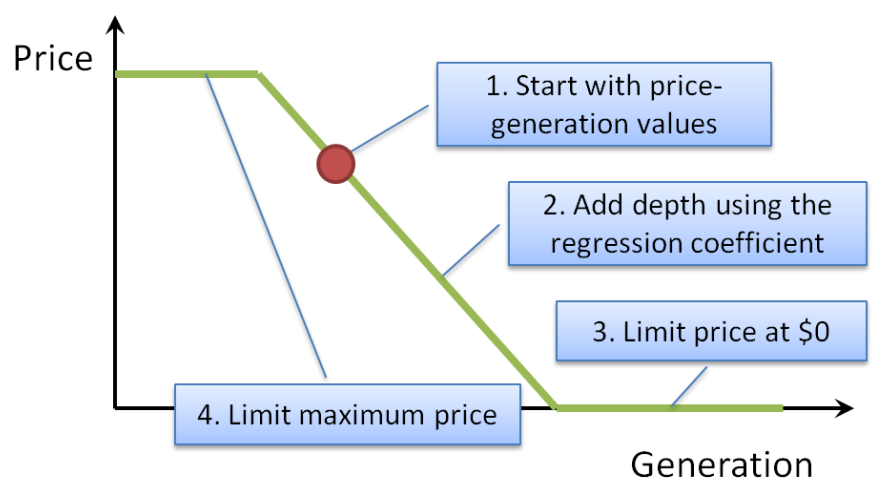

Figure 2. Procedure to create price curves for RiverWare 


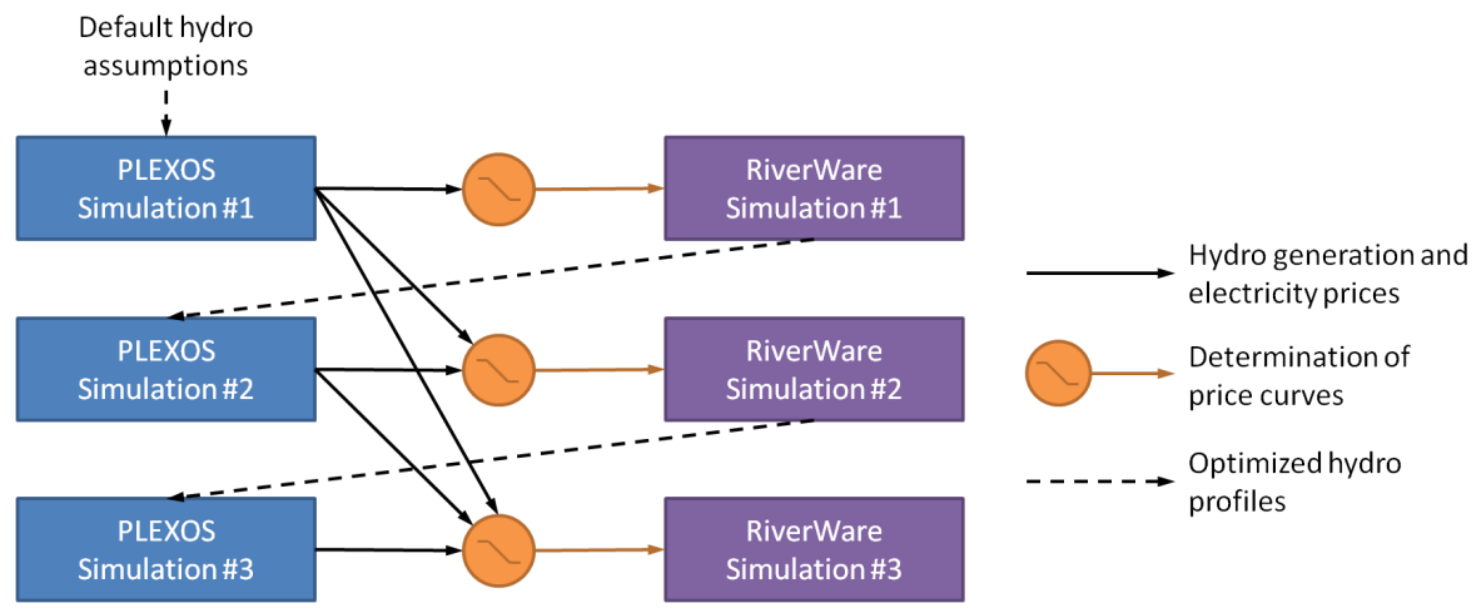

Figure 3. Diagram of the iterative process between PLEXOS and RiverWare

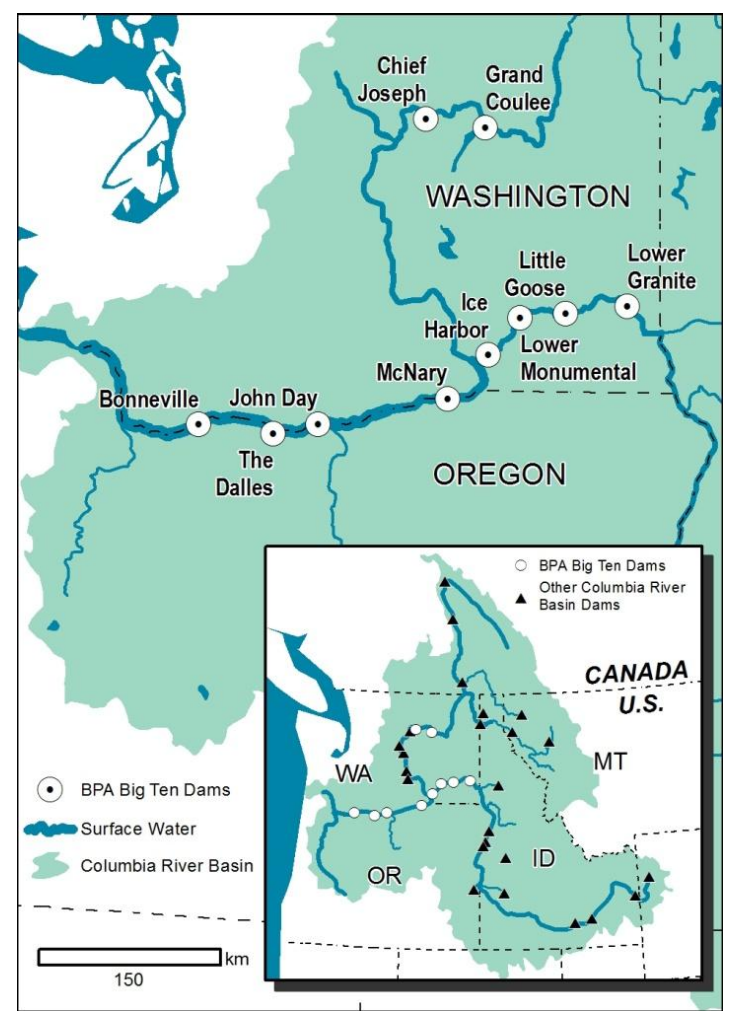

Figure 4. BPA Big Ten, Inset: Pacific Northwest Region 


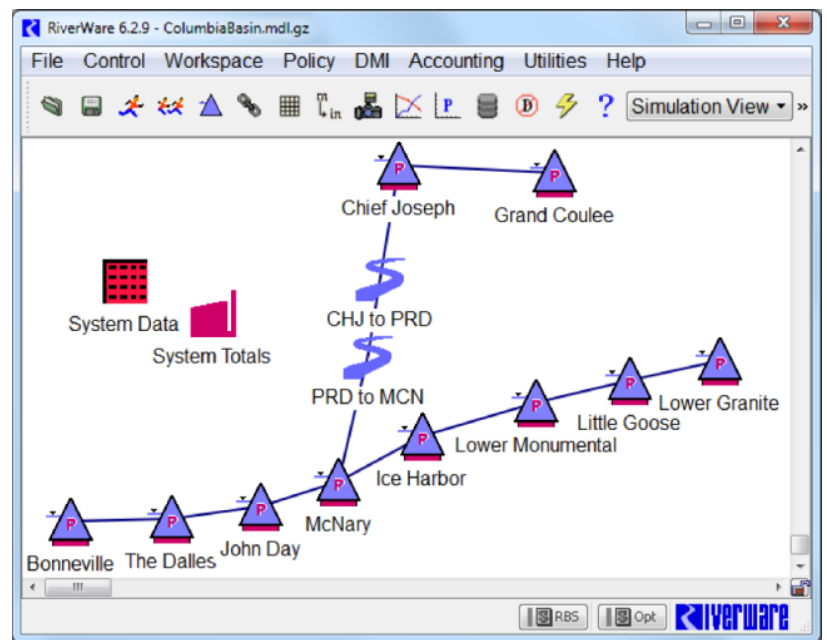

Figure 5. Representation of the Columbia River Basin in RiverWare

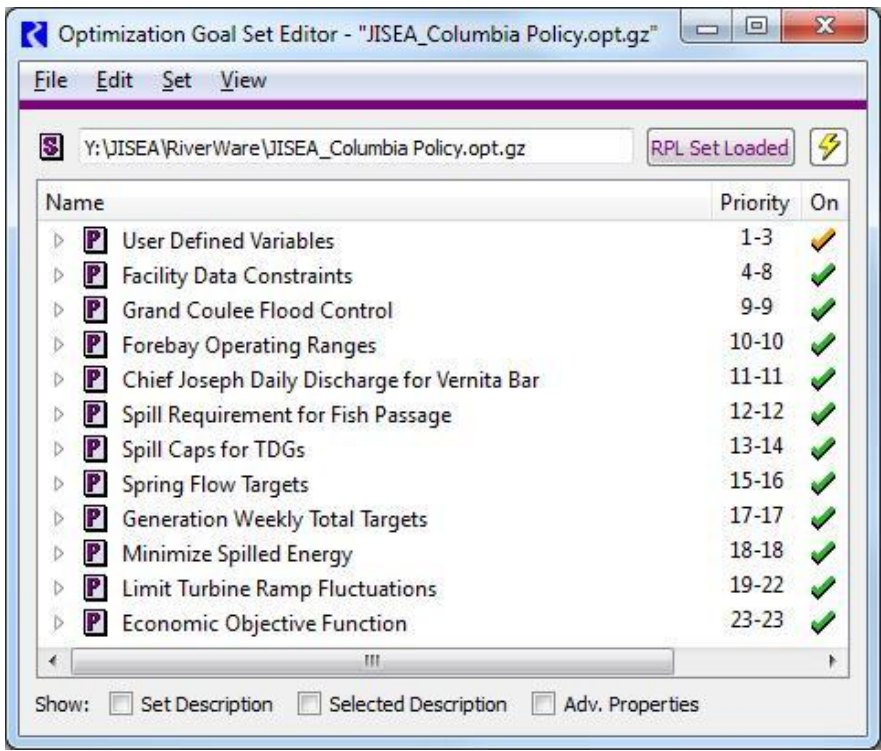

Figure 6. List of hydro policies in RiverWare 


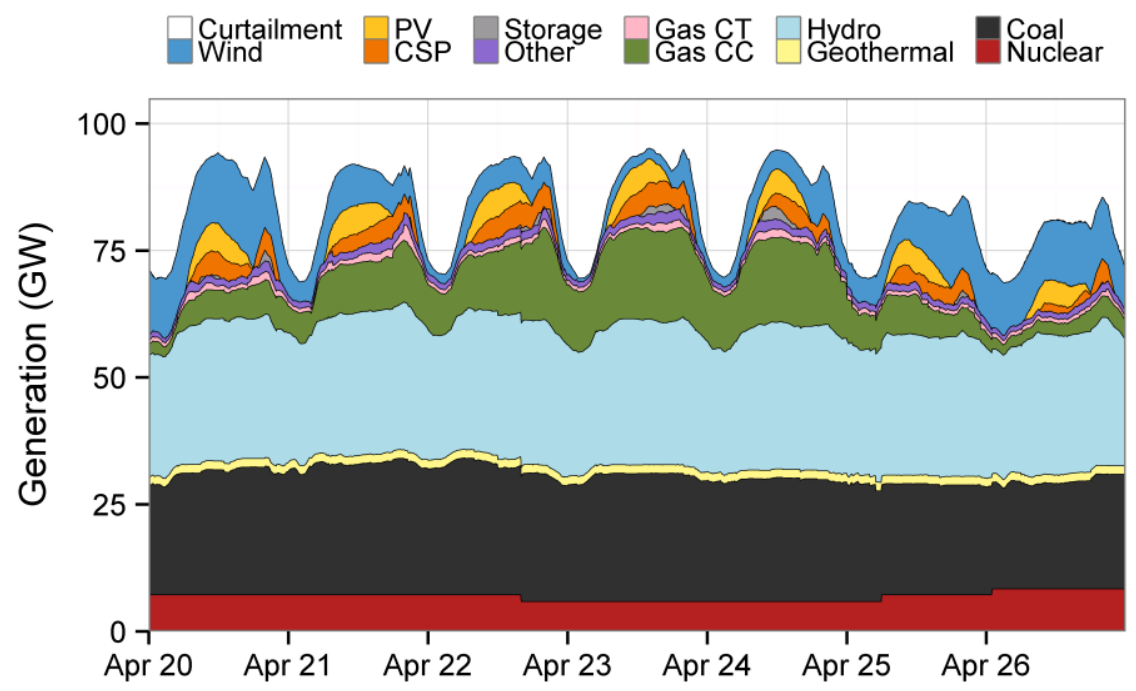

Figure 7. Five-minute dispatch of the Western Interconnection for the selected week for the BAU scenario, as determined by the first run in PLEXOS

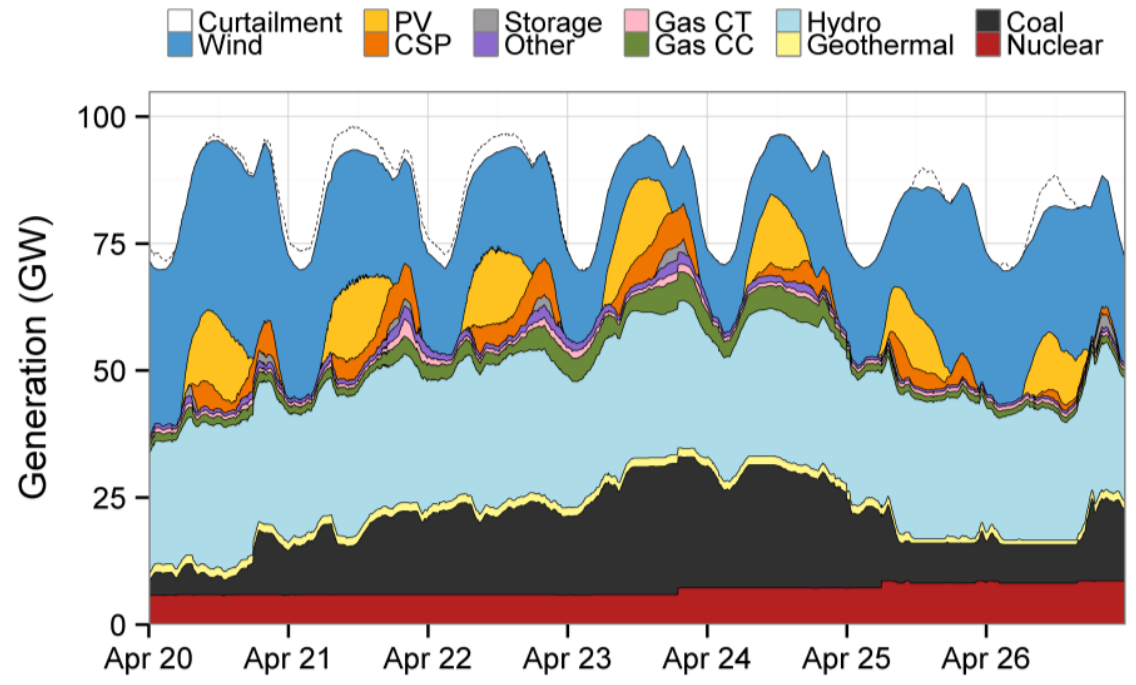

Figure 8. Five-minute dispatch of the Western Interconnection for the HiWind scenario in the first PLEXOS simulation 


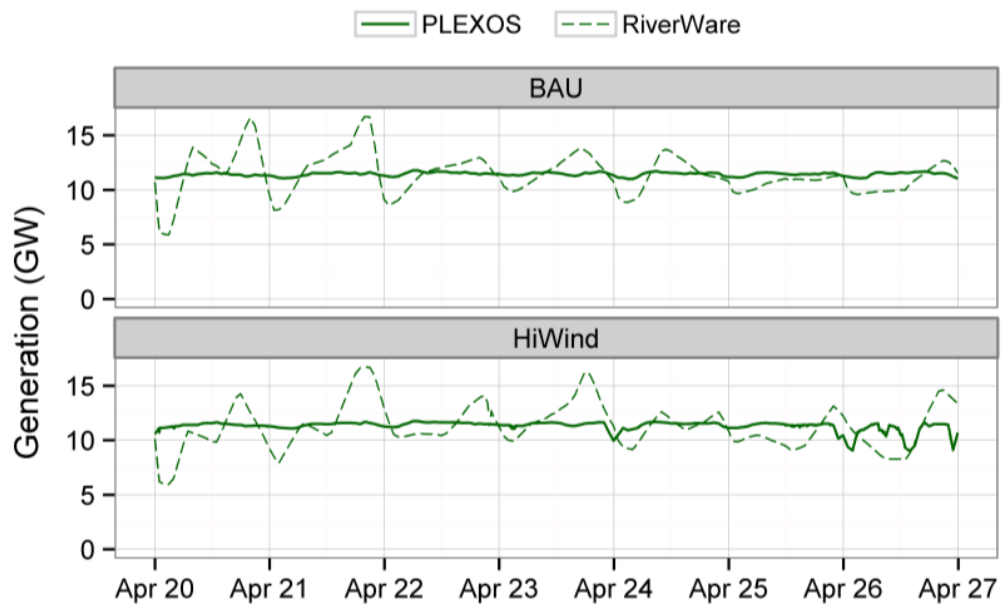

Figure 9. Total hydro generation by PLEXOS and Riverware, by scenario

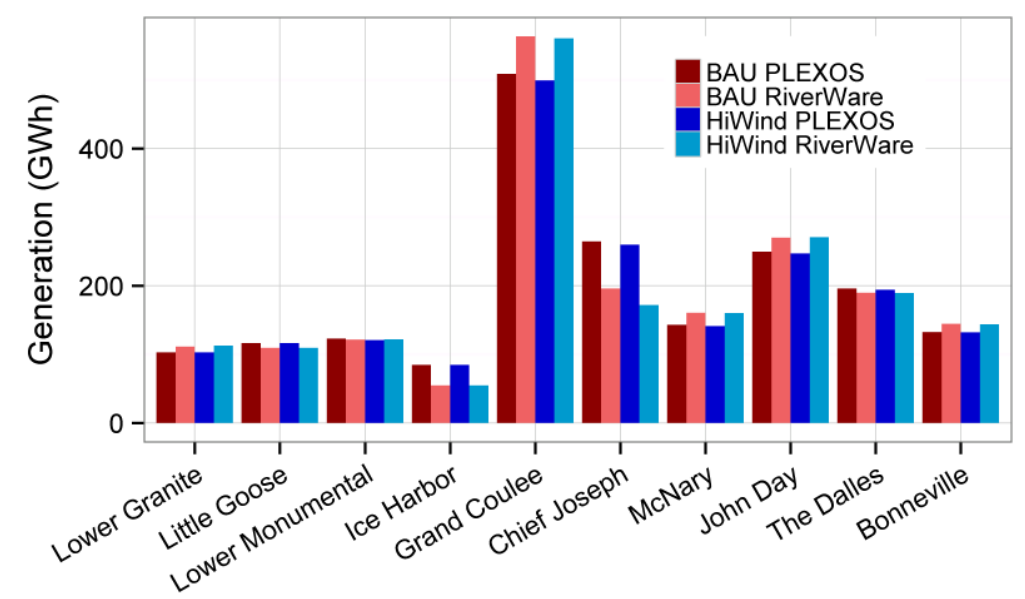

Figure 10. Energy generated at each hydropower facility by scenario 


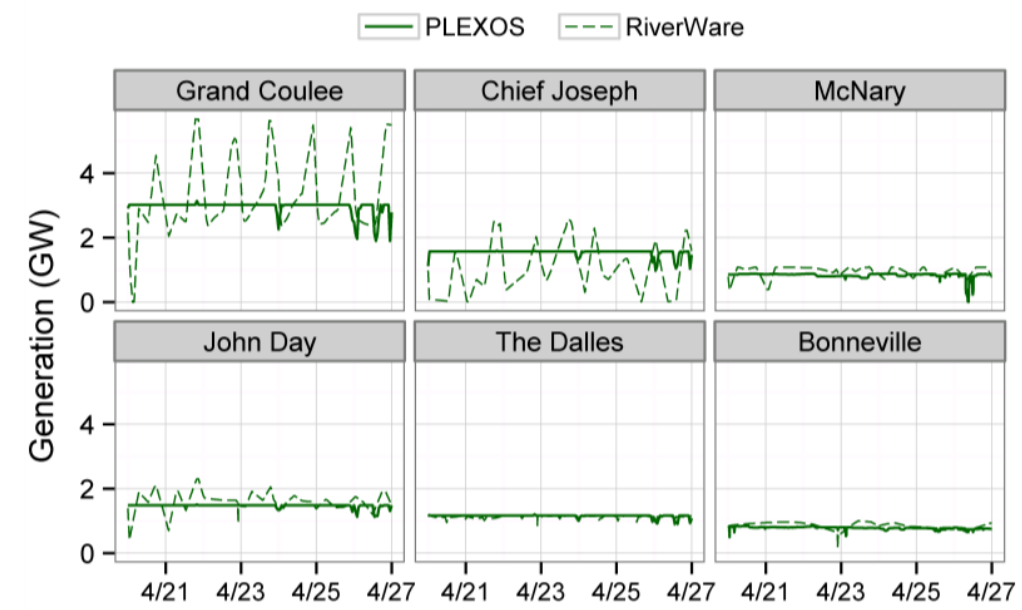

Figure 11. Generation time series generated by PLEXOS and RiverWare for Columbia River facilities in the HiWind scenario

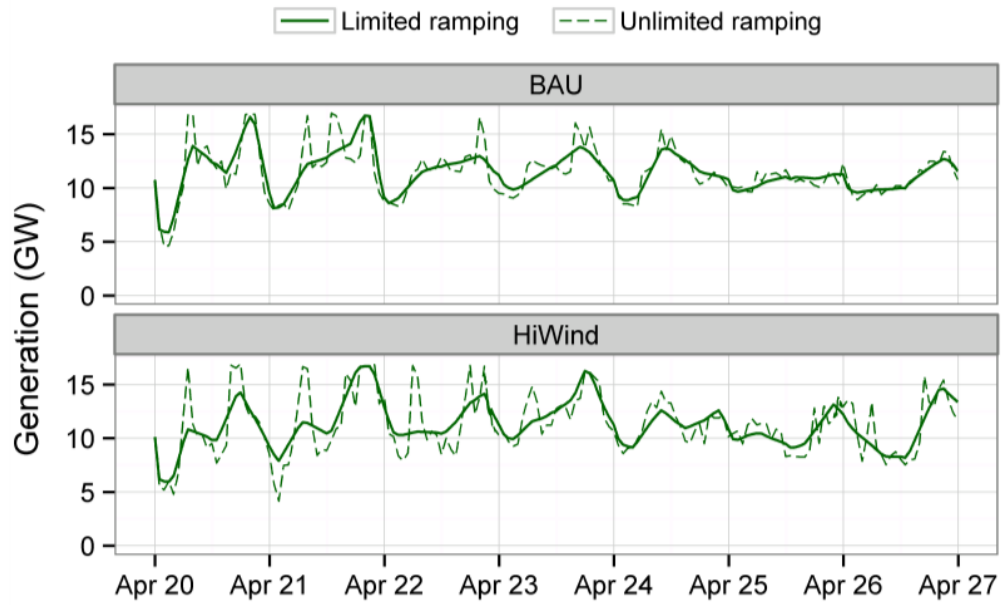

Figure 12. Total hydro generation with limited and unlimited ramping using RiverWare

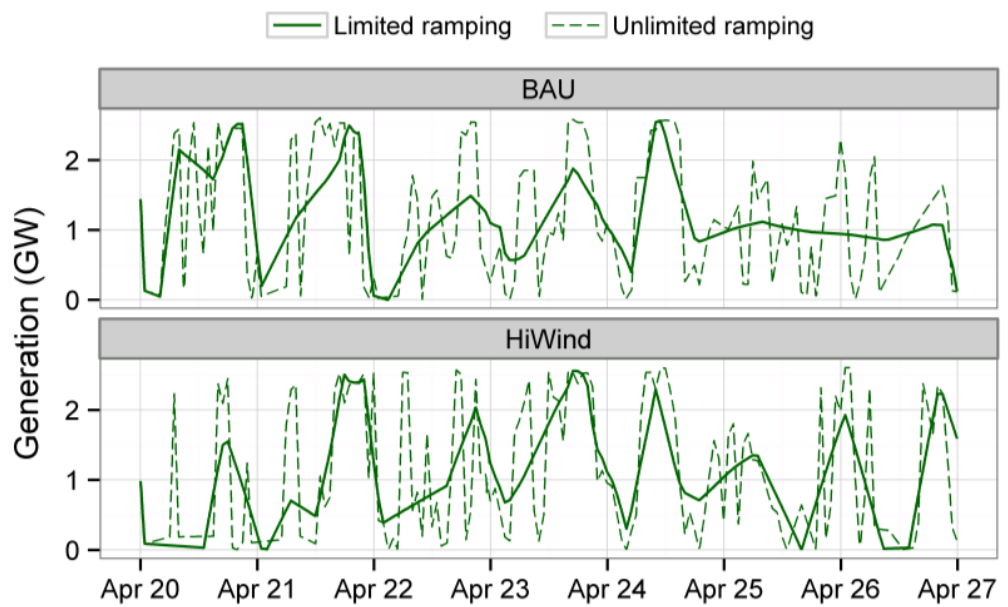

Figure 13. Power generation at Chief Joseph with and without limits on ramping using RiverWare 


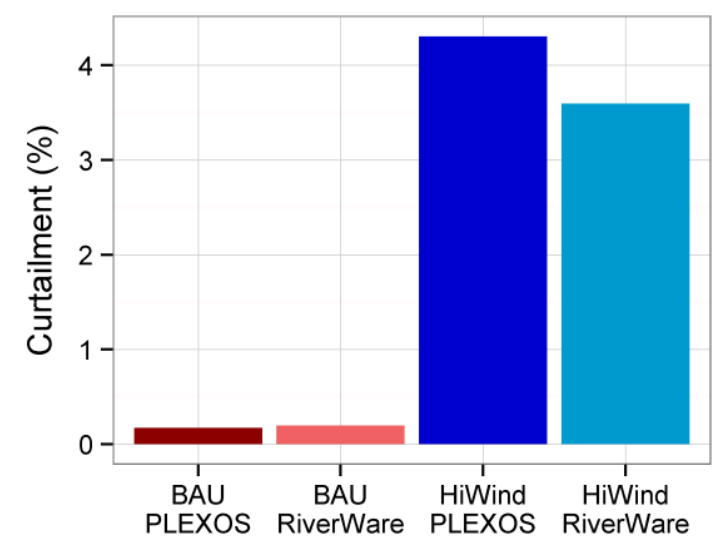

Figure 14. Relative VG curtailment by scenario for the study week

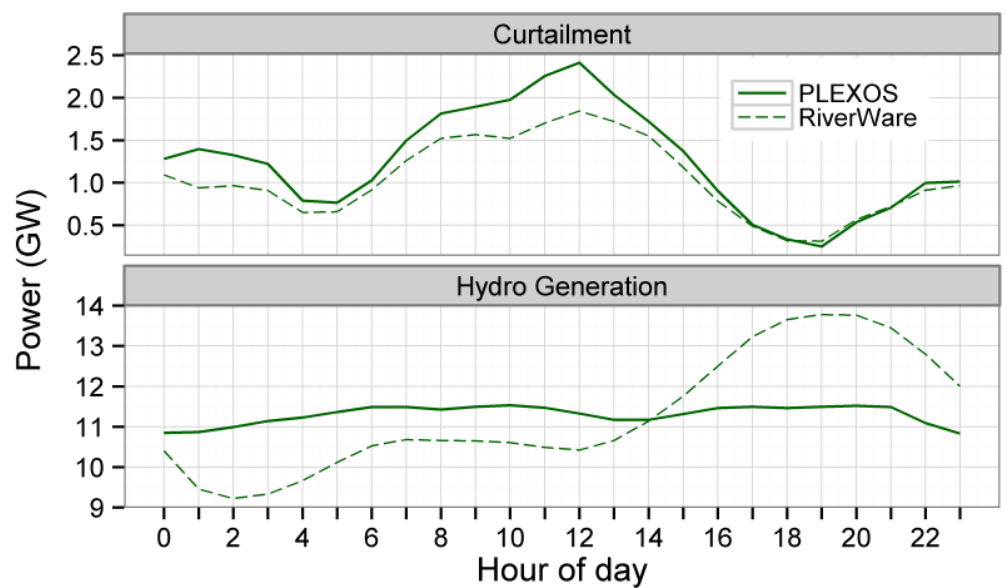

Figure 15. Hourly average VG curtailment in the Interconnection (top) and average hydro generation in the PNW region (bottom) for the HiWind scenario 


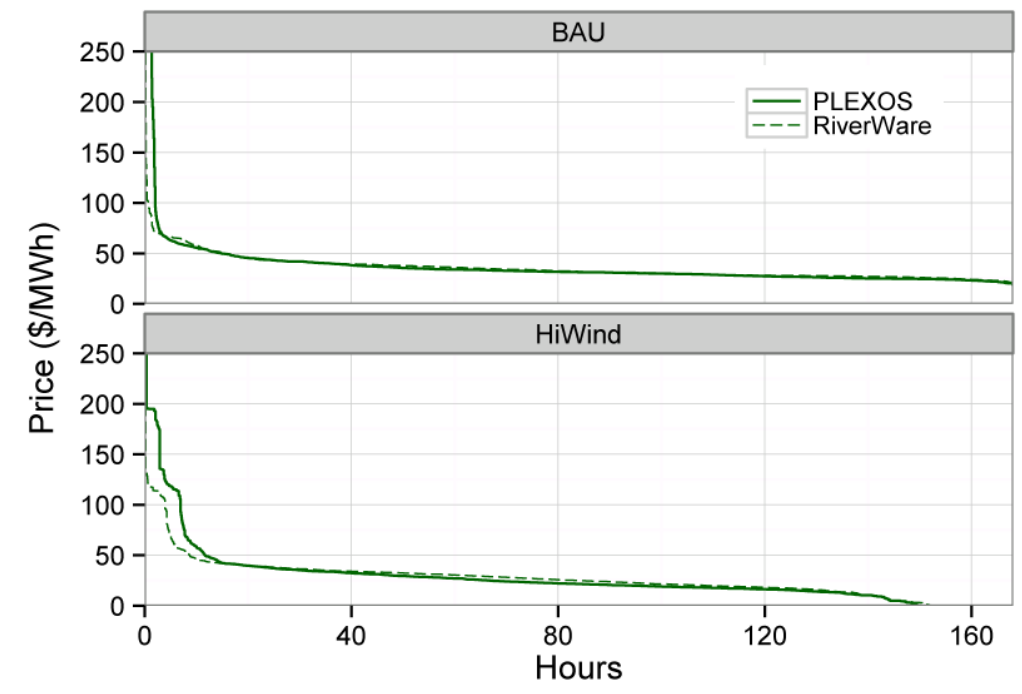

Figure 16. Interconnection-wide price duration curves

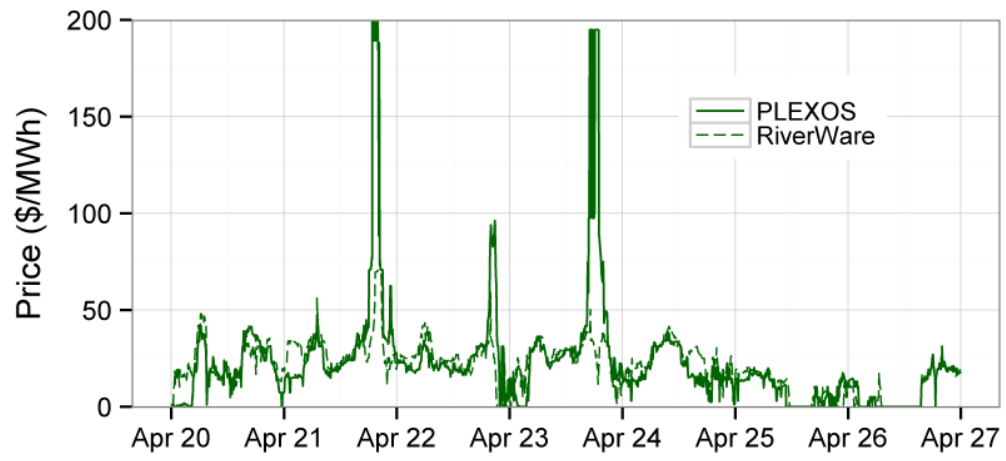

Figure 17. Five-minute price time series for the HiWind scenarios
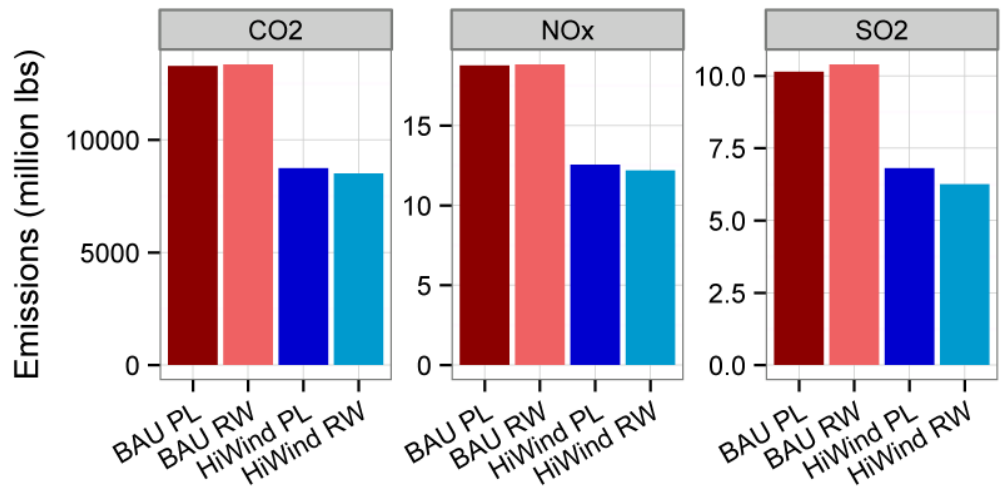

Figure 18. Total $\mathrm{CO}_{2}, \mathrm{NO}_{\mathrm{x}}$, and $\mathrm{SO}_{2}$ emissions by scenario 
Table 1: Partial Elevation vs. Storage

\begin{tabular}{cc}
\hline Elevation $(\mathrm{m})$ & Storage $\left(10^{6} \mathrm{~m}^{3}\right)$ \\
\hline 288.04 & 627.30 \\
289.56 & 674.03 \\
289.86 & 683.57 \\
290.17 & 692.87 \\
\hline
\end{tabular}

Table 2. Penetration of Variable Generation by Scenario

\begin{tabular}{cccc}
\hline Scenario & Wind & Solar & Total \\
\hline BAU & $9.4 \%$ & $3.6 \%$ & $13 \%$ \\
HiWind & $25 \%$ & $8 \%$ & $33 \%$ \\
\hline
\end{tabular}

Table 3. Price-generation curve slopes by scenario $(\$ / M W h$ for every $1 \mathrm{GW}$ of hydro)

\begin{tabular}{lcc}
\cline { 2 - 3 } & BAU & HiWind \\
\hline Without demand response & -3.04 & -2.59 \\
With demand response & -4.33 & -7.26 \\
\hline
\end{tabular}

Table 4. RiverWare Hydro Revenue by scenario (million \$)

\begin{tabular}{ccccc}
\cline { 2 - 5 } & \multicolumn{2}{c}{ Revenue } & \multicolumn{2}{c}{ Difference } \\
& TEPPC & HiWind & TEPPC & HiWind \\
\hline PLEXOS & 84.81 & 64.97 & - & - \\
Limited ramping & 87.42 & 69.33 & $2.61(3.1 \%)$ & $4.36(6.7 \%)$ \\
Unlimited ramping & 88.67 & 70.03 & $3.86(4.6 \%)$ & $5.06(7.8 \%)$ \\
\hline
\end{tabular}

Table 5. Net Generation (GWh) by Type for the PLEXOS and RiverWare Scenarios

\begin{tabular}{l|cc|cc}
\hline Generator & \multicolumn{2}{|c|}{ BAU } & \multicolumn{2}{c}{ HiWind } \\
Type & PLEXOS & RiverWare & PLEXOS & RiverWare \\
\hline Nuclear & 1,154 & 1,154 & 1,134 & 1,134 \\
Coal & 4,011 & 4,028 & 2,420 & 2,298 \\
Geothermal & 285 & 285 & 265 & 266 \\
Hydro & 4,558 & 4,561 & 4,512 & 4,512 \\
Gas CC & 1,586 & 1,539 & 426 & 497 \\
Gas CT & 173 & 170 & 155 & 154 \\
Steam & 79 & 83 & 62 & 66 \\
Other & 165 & 169 & 124 & 128 \\
Wind & 1,424 & 1,423 & 3,849 & 3,878 \\
CSP & 405 & 406 & 582 & 576 \\
PV & 323 & 322 & 823 & 828 \\
\hline
\end{tabular}


Table 6. Average Electricity Marginal Prices (\$/MWh)

\begin{tabular}{ccc}
\hline & PLEXOS & RiverWare \\
\hline BAU & 40.5 & 38.3 \\
HiWind & 30.0 & 27.0 \\
\hline
\end{tabular}

Table 7. Production Cost for the Study Week with Simplified PLEXOS Hydro Dispatch and RiverWare Redispatch

\begin{tabular}{cccc}
\hline Scenario & $\begin{array}{c}\text { PLEXOS } \\
\text { (million \$) }\end{array}$ & $\begin{array}{c}\text { RiverWare } \\
\text { (million \$) }\end{array}$ & $\begin{array}{c}\text { Reduction } \\
\text { (million \$, \%) }\end{array}$ \\
\hline BAU & 223.0 & 218.9 & $4.17(1.9 \%)$ \\
HiWind & 155.2 & 154.2 & $0.98(0.6 \%)$ \\
\hline
\end{tabular}

